\title{
Efficacy of Dose Dense Doxorubicin and Cyclophosphamide Followed by Paclitaxel versus Conventional Dose Doxorubicin, Cyclophosphamide Followed by Paclitaxel or Docetaxel in Patients with Node-Positive Breast Cancer
}

\author{
Dogan Yazılıtas' ${ }^{1}$, Mehmet Ali Nahit Sendur ${ }^{2}$, Halit Karaca ${ }^{3}$, Nuriye Ozdemir ${ }^{2}$, \\ Sercan Aksoy ${ }^{4}$, Veli Berk ${ }^{3}$, Ozan Yazıcı' ${ }^{1}$, Banu Oztürk ${ }^{3}$, Metin Ozkan ${ }^{3}$, Nurullah \\ Zengin $^{1}$, Kadri Altundag ${ }^{4}$
}

\begin{abstract}
Background: Adding taxanes to adjuvant antracycline and cyclophosphamide (AC) in combination may provide significant improvement in node-positive and high risk node-negative breast cancer (BC) patients. However, the optimal dose and the role of dose-dense (DD) chemotherapy have yet to be determined. The aim of this study was to compare the efficacy of a DD paclitaxel (P)-AC combination with conventional weekly P-AC or docetaxel D-AC combinations in patients with node-positive breast cancer. Materials and Methods: Newly diagnosed 280 node-positive BC patients diagnosed from 1998 to 2013 in three clinics were retrospectively analyzed. Demographic and medical data were collected from the medical charts. Patients were categorized to 3 groups according to treatment arms: arm A, ddAC-P; arm B, weekly P and AC combination; and arm C; $T$ and AC combination. Adjuvant trastuzumab was added for HER2-positive patients. Kaplan-Meier survival analysis was carried out for disease free survival (DFS) and overall survival (OS). The log-rank test was used to examine the statistical significance of the differences observed between the groups. Two-sided $P$ values $<0.05$ were considered statistically significant. Results: Of the total of 280 patients, 101 were in arm A, 114 in arm B and 65 in arm $C$.The median ages were 49, 50 and 46, respectively (p=0.11). Median follow-up was 39 (3-193) months. Stage, lymphovascular and perineural invasion, receptor patern, and menopausal status were similar in the 3 treatment arms, but HER2 positivity was significantly lower in arm A, compared to arms B and C $(25.7 \%$, $53.1 \%, 41.5 \%$ in arms $A, B$ and $C$, respectively; $p<0.001$ ). Also grade 3 tumors were significantly less frequent in treatment arm $A$ compared to arm $B$ and $C(27.3 \%, 56.8 \%$ and $49.2 \%$, respectively, $p=0.01)$. Afterunivariate and multivariate analysis were performed, 3-year DFS rates were $89 \%, 81 \%$, and $75 \%$, respectively $(p=0.12)$ and three year OS rates were $96.6 \%, 89 \%$, and $75 \%$ (p=0.62). Conclusions: In this study, no significant difference was found between adjuvant dose dense and conventional taxane treatment regimens.
\end{abstract}

Keywords: Breast cancer - taxanes - adjuvant chemotherapy - docetaxel - paclitaxel - dose-dense chemotherapy

Asian Pac J Cancer Prev, 16 (4), 1471-1477

\section{Introduction}

Breast cancer is the most commonly diagnosed cancer type and is the second leading cause of death due to cancer among women all over the world and breast cancer alone is expected to account for $29 \%$ of all new cancers among women (Siegel et al., 2014). However, surgery is the only curative treatment modality of early breast cancer patients, adjuvant systemic chemotherapy following surgery have significant effect on disease free survival
(DFS) and overall survival (OS) (Early Breast Cancer Trialists' Collaborative, 2005; Gogia et al., 2014). In earlystage breast cancer, cyclophosphamide-methotrexate-5 fluorouracil (CMF) regimen was the first combination regimen that significantly improved DFS and OS (Bonadonna et al., 1995). Polychemotherapy withCMFor antracycline-containing regimens significantly improved risk of recurrence and death (1998). In following years, the effectiveness of anthracyclines and than taxanes were demonstrated and started to administer in adjuvant

${ }^{1}$ Department of Medical Oncology, Ankara Numune Education and Research Hospital, ${ }^{2}$ Department of Medical Oncology, Faculty of Medicine, Ylldirlm Beyazıt University, ${ }^{4}$ Department of Medical Oncology, Hacettepe University Cancer Institute, Ankara, ${ }^{3}$ Gaziosmapaşa University Faculty of Medicine, Department of Medical Oncology, Tokat,Turkey *For correspondence: masendur@ yahoo.com.tr 
setting (Ozdemir et al., 2012). Despite in some studies no significant OS and DFS difference was shown between adjuvant antracycline-combinations and CMF regimens the superiority of antracycline-containing regimens were shown in many randomized trials and in Early Breast Cancer Trialists' Collaborative Group (EBCTCG) overview of randomized trials antracycline-containing regimens showed $12 \%$ further reduction of annual recurrence risk and $11 \%$ further reduction risk of death compared to CMF regimen (Levine et al., 1998; Bang et al., 2000; Martin et al., 2003; Kimura et al., 2010).

The antitumor efficacy of taxanes were firstly shown with adding to doxorubicin plus cyclophosphamide in metastatic breast cancer patients (Nabholtz et al., 2003; Bontenbal et al., 2005). In a randomized phase III BCIRG (Breast Cancer International Research Group) 001 trial adding docetaxel to doxorubicin plus cyclophosphamide (AC) significantly improved DFS and OS with a median 124 months follow-up in the adjuvant treatment of nodepositive breast cancer (Mackey et al., 2013).

In another phase III trial, adding paclitaxel to AC regimen significantly improved DFS and OS in the adjuvant treatment of node-positive breast cancer (Henderson et al., 2003). In ECOG (Eastern Cooperative Oncology Group) 1199 trial the efficacy of weekly and 3-weekly docetaxel or paclitaxel after four cycles of standard AC regimen was investigated in 4.950 women with node-positive or high-risk node-negative breast cancer (Sparano et al., 2005; 2008). In this trial both paclitaxel and docetaxel regimens emerged similar DFS efficacy with no difference between weekly therapy and 3-weekly regimens.In the subgroup analyses of this study, significant DFS benefit of dose-dense therapy with paclitaxel was found (HR: 1.27, $\mathrm{p}=0.006$ ), whereas no significant benefit was reported with dose-dense docetaxel arms. Five-year DFS rates were $81.5 \%$ and $81.2 \%$ in weekly paclitaxel and docetaxel every three weeks arms, respectively. In addition to shown benefit of adding taxanes in node-positive breast cancer patients, adding docetaxel to AC regimen compared to fluorouracil,doxorubicin plus cyclophosphamide (FAC) regimen significantly improved DFS in high risk nodenegative breast cancer patients (Martin et al., 2010; Sakr et al., 2013).

A meta-analysis of among 100,000 breast cancer patients in 123 randomised trials from EBCTCG showed that adding taxanes to antracycline-based chemotherapy significantly improved breast cancer specific mortality (Early Breast Cancer Trialists' Collaborative et al., 2012).

Despite many different regimens are used in adjuvant setting, the relapse risks of these patients are still high. Therefore, in order to reduce the risk of relapse, dose dense schedules began to be discussed. The fundamental of this approach is to shorten the time intervals between standard chemotherapy dosages, which has based on NortonSimpson hypothesis. The rationale of dose dense regimen is predicting to kill more cancer cells due to Gompertzian growth pattern of tumor cells (Norton and Simon, 1986). In a phase III CALGB (Cancer and Leukemia Group B) 9741 trial, dose dense treatment demonstrated significant DFS (RR=0.74, $\mathrm{p}=0.01$ ) and OS ( $R=0.69, \mathrm{p}=0.013$ ) improvement compared to standart regimens every three weeks in patients with node-positive breast cancer (Citron et al., 2003). In GONO-MIG (Italian Gruppo Oncologico Nord Ovest-Mammella Inter Gruppo) trial no significant DFS and OS difference was observed with adjuvant fluorouracil, epirubicin, and cyclophosphamide (FEC) administered every 3 weeks compared to every 2 weeks with filgrastim support in high risk node-negative and node positive breast cancer patients (Venturini et al., 2005). In a Hellenic Cooperative Oncology Group HE 10/00 phase III trial no DFS and OS benefit was detected with dosedense sequential epirubicin and paclitaxel compared to the concurrent administration in patients with node-positive breast cancer with a median 76 month follow-up (Gogas et al., 2012).

Despite some of randomized trials reported results similar to Norton's study, there is a contradictory results leading to discussions of using of dose dense regimens. Therefore, we aimed to compare the effectiveness of conventional chemotherapy regimens with dose dense regimens in high risk node positive breast cancer patients.

\section{Materials and Methods}

Between January 1998 and May 2013, operated and lymph node positive 280 patients with breast cancer from 3 cancer centers were retrospectively analyzed. At the time of diagnosis of breast cancer patients who were treated with adjuvant taxanes were enrolled to the study. According to chemotherapy regimens patients were divided into three groups. The dose-dense doxorubicin plus cyclophosphamide followed with paclitaxel (ddAC-P group; doxorubicin $60 \mathrm{mg} / \mathrm{m}^{2}$, cyclophosphamide 600 $\mathrm{mg} / \mathrm{m}^{2}$ every two weeks for four cycles and following that paxlitaxel $175 \mathrm{mg} / \mathrm{m}^{2}$ every two weeksfor four cycles). One of the conventional chemotherapy groups were doxorubicin plus cyclophosphamide followed with weekly paclitaxel (AC-P group; doxorubicin $60 \mathrm{mg} / \mathrm{m}^{2}$, cyclophosphamide $600 \mathrm{mg} / \mathrm{m}^{2}$ for four cycles with 3 week intervals and following that paxlitaxel $80 \mathrm{mg} / \mathrm{m}^{2}$ weekly for 12 weeks) and the third patient group was treated with conventional doxorubicin plus cyclophosphamide followed with docetaxel (AC-D; doxorubicin $60 \mathrm{mg}$ / $\mathrm{m}^{2}$, cyclophosphamide $600 \mathrm{mg} / \mathrm{m}^{2}$ every three weeks for four cycles and following that docetaxel $100 \mathrm{mg} /$ $\mathrm{m}^{2}$ for four cycles with 3 week intervals). Patients in the dose dense arm had primary filgrastime or lenograstim prophylaxis for 5 days beginning after 72 hours following the chemotherapy infusion. Chemotherapy toxicities are evaluated according to Common Toxicity Criteria (CTC) Version 4.0.

Demographic and medical data including age, menopausal status, treatment history and comorbid diseases were collected from the medical charts. Tumors were graded according to the modified Bloom-Richardson scoring system and staged according to the TNM (tumor-node-metastases) criteria. The data on estrogen receptor (ER), progesteron receptor (PR) and HER-2/ neu were obtained through standard clinical testing, using immunohistochemistry (IHC) for ER and PR and the HerceptTest for HER-2/neu. For ER and PR; receptor positivity was based on more than $1 \%$ of cells testing 
positive. The patients were categorized as triple-negative if they were negative for ER, PR and HER-2/neu.

Statistical analysis

Statistical analyses was performed by using SPSS for Windows version 18.0 (SPSS, Chicago, IL). Baseline characteristics of 3 treatment groups were compared by $\mathrm{X}^{2}$ tests (for categorical variables) or two sample t tests (for continuous variables). Tumors with missing values were omitted from the analyses. The data were retrospectively analyzed for DFS and OS according to the treatment groups. Kaplan-Meier survival analysis was carried out for DFS and OS. The log-rank test was used to examine the statistical significance of the differences observed between the groups. Two-sided $\mathrm{P}$ values of $<0.05$ were considered statistically significant. Factors associated significance $(\mathrm{p}<0.05)$ in the univariate analyses were encountered into a Cox proportional-hazards model in a forward, stepwise fashion in order to analyze their effects on the outcomes of histological grade, treatment group, T-stage and DFS.

\section{Results}

A total of 280 axillary node-positive breast cancer patients who received taxanes as adjuvant treatment

Table 1. Baseline Demographic Characteristics According to the Treatment Group

\begin{tabular}{|c|c|c|c|c|}
\hline Characteristic & $\begin{array}{c}\mathrm{ddAC}-\mathrm{P}(\mathrm{n}=101) \\
\mathrm{n}(\%)\end{array}$ & $\begin{array}{c}\mathrm{AC}-\mathrm{P}(\mathrm{n}=114) \\
\mathrm{n}(\%)\end{array}$ & $\begin{array}{c}\mathrm{AC}-\mathrm{D}(\mathrm{n}=65) \\
\mathrm{n}(\%)\end{array}$ & P-Value* \\
\hline \multicolumn{5}{|c|}{ Histology of primary tumor } \\
\hline IDC & $84(83.2)$ & $86(75.5)$ & $52(81.3)$ & \multirow[t]{4}{*}{0.42} \\
\hline ILC & $4(4)$ & $4(3.5)$ & $2(3.1)$ & \\
\hline Mixed & $9(8.8)$ & $20(17.5)$ & $10(15.6)$ & \\
\hline Others & 4 (4) & $4(3.5)$ & - & \\
\hline \multicolumn{5}{|l|}{ Age } \\
\hline$<50$ & $52(51.5)$ & $66(57.9)$ & $43(66.2)$ & \multirow[t]{2}{*}{0.17} \\
\hline$\geq 50$ & $49(48.5)$ & $48(42.1)$ & $22(33.8)$ & \\
\hline \multicolumn{5}{|l|}{ Menopausal status } \\
\hline Premenopausal & $46(45.5)$ & $65(57.0)$ & $37(57.8)$ & \multirow[t]{3}{*}{0.11} \\
\hline Perimenopausal & $14(13.9)$ & $6 \quad(5.3)$ & $8(12.5)$ & \\
\hline Postmenopausal & $41(40.6)$ & $43(37.7)$ & $19(29.7)$ & \\
\hline \multicolumn{5}{|l|}{ Estrogen Receptor } \\
\hline Positive & $69(69)$ & $69(60.5)$ & $38(59.4)$ & \multirow[t]{2}{*}{0.33} \\
\hline Negative & $31(31)$ & $45(39.5)$ & $26(40.6)$ & \\
\hline \multicolumn{5}{|c|}{ Progesterone Receptor } \\
\hline Positive & $69(68.3)$ & $67(59.8)$ & $39(60.9)$ & \multirow[t]{2}{*}{0.28} \\
\hline Negative & $32(31.7)$ & $45(40.2)$ & $25 \quad(9.1)$ & \\
\hline \multicolumn{5}{|l|}{$\operatorname{HER} 2(+)$} \\
\hline Positive & $26(25.7)$ & $60(53.1)$ & $27(41.5)$ & \multirow[t]{2}{*}{$<0.001$} \\
\hline Negative & $75(74.3)$ & $54(47.4)$ & $38(58.5)$ & \\
\hline \multicolumn{5}{|l|}{ Grade } \\
\hline I & $5 \quad(5.7)$ & 4 (3.6) & 1 (1.6) & \multirow[t]{3}{*}{0.01} \\
\hline II & $59(67.0)$ & $44(39.6)$ & $30(49.2)$ & \\
\hline III & $24(27.3)$ & $63(56.8)$ & $30(49.2)$ & \\
\hline \multicolumn{5}{|l|}{ LVI } \\
\hline Positive & $50(49.5)$ & $57(50.0)$ & $32(49.2)$ & \multirow[t]{2}{*}{0.99} \\
\hline Negative & $51(50.5)$ & $57(50.0)$ & $33(50.8)$ & \\
\hline \multicolumn{5}{|l|}{ PNI } \\
\hline Positive & $30(34.1)$ & $18(24.3)$ & $12(31.6)$ & \multirow[t]{2}{*}{0.39} \\
\hline Negative & $58(65.9)$ & $56(75.7)$ & $26(68.4)$ & \\
\hline \multicolumn{5}{|l|}{ T-Stage at diagnosis } \\
\hline $\mathrm{T} 1$ & $28(27.7)$ & $16(14.3)$ & $9(14.1)$ & \multirow{4}{*}{0.91} \\
\hline $\mathrm{T} 2$ & $57(56.4)$ & $63(56.3)$ & $39(60.9)$ & \\
\hline T3 & $15(14.9)$ & $30(26.7)$ & $14(21.9)$ & \\
\hline $\mathrm{T} 4$ & $1(1.0)$ & $3(2.7)$ & $2(3.1)$ & \\
\hline \multicolumn{5}{|l|}{ Lymph node status } \\
\hline $\mathrm{N} 1$ & $47(46.5)$ & $47(41.2)$ & $23(35.4)$ & \multirow[t]{3}{*}{0.28} \\
\hline $\mathrm{N} 2$ & $28(27.7)$ & $36(31.6)$ & $16(24.6)$ & \\
\hline N3 & $26(25.8)$ & $31(27.2)$ & $26(40.0)$ & \\
\hline \multicolumn{5}{|l|}{ TNM } \\
\hline Stage IIA & $18(17.8)$ & $13(11.4)$ & $6 \quad(9.2)$ & \\
\hline Stage IIB & $29(28.7)$ & $26(22.8)$ & $12(18.5)$ & 0.47 \\
\hline Stage IIIA & $27(26.7)$ & $41(36.0)$ & $20(30.8)$ & \\
\hline Stage IIIB & $1(1.0)$ & $1 \quad(0.9)$ & 1 (1.5) & \\
\hline Stage IIIC & $26(25.8)$ & $33(28.9)$ & $26(40.0)$ & \\
\hline
\end{tabular}

*Bold value indicates $\mathrm{P}<0.05$; Abbreviations: AC-D; doxorubicin plus cyclophosphamide following docetaxel, AC-P; doxorubicin plus cyclophosphamide following paxlitaxel weekly, ddAC-P; doşe-dense doxorubicin plus cyclophosphamide following paxlitaxel, HER, Hercept test for Her2/Neu; IDC, Invasive ductal carcinoma; ILC, Invasive lobular carcinoma; LVI, lymphovascular invasion; PNI, Perineural invasion; TNM, tumour-node-metastases 
Table 2. Patients Treatment Modalities According to the Taxane Treatments

\begin{tabular}{|c|c|c|c|c|}
\hline Characteristic & $\begin{array}{c}\text { ddAC-P }(\mathrm{n}=101) \\
\mathrm{n}(\%)\end{array}$ & $\begin{array}{c}\text { AC-P }(\mathrm{n}=114) \\
\mathrm{n}(\%)\end{array}$ & $\begin{array}{c}\mathrm{AC}-\mathrm{D}(\mathrm{n}=65) \\
\mathrm{n}(\%)\end{array}$ & P-Value* \\
\hline \multicolumn{5}{|l|}{ Type of Surgery } \\
\hline MRM & $67(66.3)$ & $99(86.8)$ & $54(83.1)$ & \multirow[t]{2}{*}{0.005} \\
\hline BCS & $34(33.7)$ & $15(13.2)$ & $11(16.9)$ & \\
\hline \multicolumn{5}{|l|}{ Trastuzumab } \\
\hline Yes & $26(25.7)$ & $59(51.8)$ & $24(37.0)$ & \multirow[t]{2}{*}{$<0.00$} \\
\hline No & $75(74.3)$ & $55(48.2)$ & $41(63.0)$ & \\
\hline \multicolumn{5}{|c|}{ Adjuvant Radiotherapy } \\
\hline Yes & 94 (96.9) & $108(94.7)$ & $61(95.3)$ & \multirow[t]{2}{*}{0.73} \\
\hline No & $3(3.1)$ & $6 \quad(5.3)$ & $3(4.7)$ & \\
\hline \multicolumn{5}{|c|}{ Hormonal treatment } \\
\hline Yes & $81(84.4)$ & $74(64.9)$ & $45(69.2)$ & \multirow[t]{2}{*}{0.004} \\
\hline No & $15(15.6)$ & $40(35.1)$ & $20(30.8)$ & \\
\hline
\end{tabular}

*Bold value indicates $\mathrm{P}<0.05$; Abbreviations: AC-D; doxorubicin plus cyclophosphamide following docetaxel, AC-P; doxorubicin plus cyclophosphamide following paxlitaxel weekly, ddAC-P; doşe-dense doxorubicin plus cyclophosphamide following paxlitaxel, MRM; modified radical mastectomy, BCS; breast conserving surgery

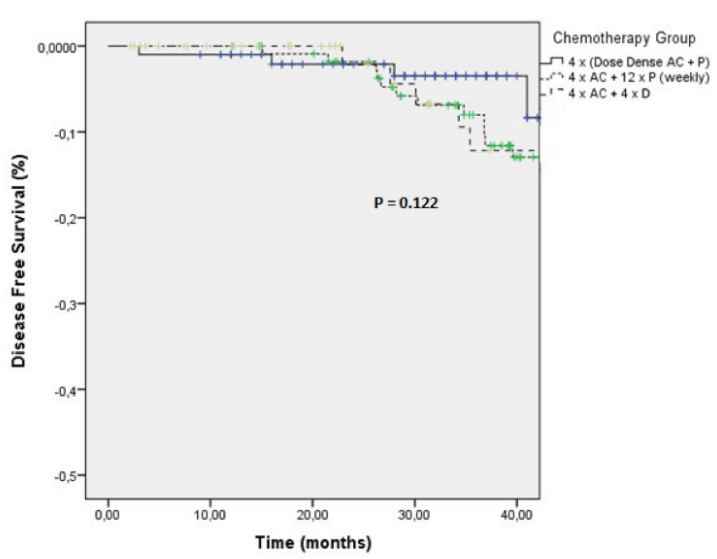

Figure 1. Disease-free Survival Analyses According to the Treatment Groups After Risk Factors Adjusted

between 1998 and 2013 years were retrospectively analyzed. In ddAC-P, AC-P and AC-D arms 101, 114 and 65 patients were enrolled, respectively.All of the participants were female and the median age was 49 (25-81), 46 (20-77) and 43 (26-69) in ddAC-P, AC-P and AC-D arms, respectively $(\mathrm{p}=0.17)$. The median follow-up time for this analysis was 39 (3-163) months. Median follow-up was 33 months (4-65), 49 (12-165) months and 43 months (11-142) in ddAC-P, AC-P and AC-D arms, respectively. Baseline clinico-pathologic characteristics of the participants are described in Table 1. There were no apparentdifferences inhistopathological subtype, ER and PR status, tumor stage, menopausal status, perineural and lymphovascular invasion ratios between treatment groups. There were also no apparent differences in baseline nodal stage $(p=0.28)$, tumor size $(p=0.91)$ and tumor stage $(\mathrm{p}=0.47)$ between taxanetreatment arms. However,histopathological grade and HER-2 status were significantly different betweentaxane treatment groups. HER2-positivity was reported in $25.7 \%, 53.1 \%$ and 41.5\% in ddAC-P, AC-P and AC-D arms,respectively $(\mathrm{p}<0.001)$. In ddAC-P arm, rate of grade 3 tumor was also significantlylowercompared to AC-P and AC-D arms $(27 \%, 56 \%$ and $49 \%$, respectively, $\mathrm{p}=0.01)$.

The treatment modalities applied to patients were summarized in Table 2. Although all of the patients with HER-2 positive tumors in ddAC-P arm weretreated with adjuvant trastuzumab, in AC-P arm 59 out of 60 patients

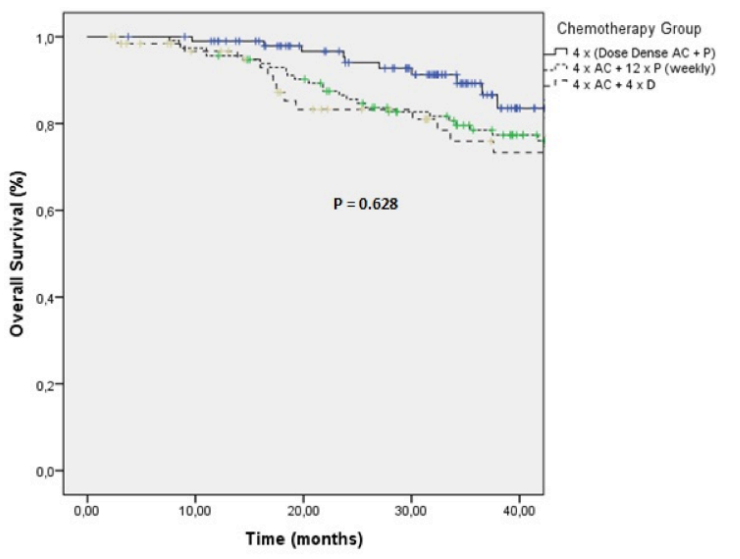

Figure 2. Overall Survival Analyses According to the Treatment Groups

Table 3. Toxicities in ddAC-P arm According to the CTCAE, Version 4.0

\begin{tabular}{|c|c|c|}
\hline CGrade 3-4 Toxicity & $\begin{array}{c}\text { AC treatment } \\
\mathrm{n}=101(\%)\end{array}$ & $\begin{array}{c}\text { Paclitaxel treatment } \\
\mathrm{n}=101(\%)\end{array}$ \\
\hline Neutropenia & $22(21.7)$ & $2(1.98)$ \\
\hline Anemia & $1 \quad(0.9)$ & - \\
\hline Neuropathy & - & $4 \quad(3.9)$ \\
\hline Nausea-vomiting & $2 \quad(1.9)$ & - \\
\hline Acute allergic reaction & - & $2(1.98)$ \\
\hline Neutropenic Fever & $11(10.8)$ & - \\
\hline Chemotherapy Delay & $22(21.7)$ & $15(14.8)$ \\
\hline Dose Reduction & $2 \quad(1.9)$ & $8 \quad(7.9)$ \\
\hline
\end{tabular}

and in AC-D arm 24 out of 27 patients with HER2-positive tumors were treated with adjuvant trastuzumab at the time of analyses. The number of patients that had radiotherapy were equally dispersed between treatment groups. Adjuvant hormonal treatment and breast conserving surgery were performed significantly higher in ddAC-P group.

\section{Efficacy}

Due to the lower the median DFS and OS did not reached in all three arms. Three-year DFS rates were; $89 \%, 78 \%$ and $75 \%$ in ddAC-P, AC-P and AC-D arms, respectively $(\mathrm{p}=0.014)$.In univariate analysis the histologic grade at time of diagnosis had significant effect on PFS ( $p=0.002)$ whereas no effect of HER2- 
positivity ( $\mathrm{p}=0.51)$, receptor positivity $(\mathrm{p}=0.42)$, adjuvant trastuzumab $(\mathrm{p}=0.55)$ and hormonal treatments $(\mathrm{p}=0.40)$ were found. Univariate analyses demonstrated that 3-year DFS rates were significantly decreased in patients with poorly differentiated tumors and advanced disease. In multivariate analyses, we demonstrated that tumor stage $(\mathrm{p}=0.03)$ and histological grade $(\mathrm{p}=0.01)$ had significant effect on DFS. After multivariate analyses performed no significant DFS was observed between dose dense and conventional chemotherapy regimens $(\mathrm{p}=0.12)$ (Figure 1). Three year OS rates were $96.6 \%, 89 \%$, and $75 \%$ in ddAC-P, AC-P and AC-D arms, respectively ( $\mathrm{p}=0.62)$ (Figure 2).

\section{Toxicity}

Due to retrospective design of study, especially in conventional chemotherapy arms we did not collect reliable data considering chemotherapy toxicity. Adverse events of ddAC-P arm were shown in Table 3. In dose dense arm, dose reduction was performed in $9.8 \%$ of the patients and chemotherapy delay was observed in $36.5 \%$ of the patients due to grade 3-4 adverse events.

\section{Discussion}

In our study, 3-year DFS rates were; $89 \%, 78 \%$ and $75 \%$ in ddAC-P, AC-P and AC-D arms, respectively $(\mathrm{p}=0.014)$. Due to unequal distribution of HER2 positivity and histological grade between three arms univariate analysis and then multivariate analyses were performed. In univariate analyses histologic grade at time of diagnosis had significant effect on PFS ( $\mathrm{p}=0.002)$ whereas no effect of HER2-positivity ( $\mathrm{p}=0.51)$ were found. In addition to, in univaraiate analyses no significant effect of surgery type and hormonal treatment on DFS and OS was found. In multivariate analyses, we demonstrated that tumor stage $(p=0.03)$ and histological grade $(p=0.01)$ had significant effect on DFS. After multivariate analyses performed no significant DFS was observed between dose dense and conventional chemotherapy regimens. Three year OS rates were also similar in three treatment arms.

In a recent published phase III NSABP (National Surgical Adjuvant Bowel Project) B-38 trial, 4.894 patients with node-positive breast cancer randomized to six cycles of docetaxel, doxorubicin, and cyclophosphamide (TAC) or four cycles of DD AC followed by four cycles of DD paclitaxel or DD AC with paclitaxel every 3 weeks with four cycles of gemcitabine added to the DD paclitaxel (Swain et al., 2013). In this trial adding gemcitabine to dose dense chemotherapy did not improve outcomes and no significant difference was reported between TAC and DD AC with paclitaxel regimens with different toxicity profile. In randomized phase III BCIRG 005 trial, adding sequential and combination docetaxel regimens to AC showed similar efficacy with different toxicity profile(Eiermann et al., 2011). According to efficacy results of this two trials both sequential or combination or dose dense anthracycline and taxane-based regimens can be used for patients with node-positive breast cancerwith different toxicity profiles.

The first dose-dense NCI (National Cancer Institute)
Milan Study compared the efficacy of alternating treatment strategy of 3-week cycles of CMF followed with one dose of doxorubicin with a sequential therapy regimen consisting of 4 cycles of doxorubicin every three weeks followed by 8 cycles of CMF (Bonadonna et al., 2004). In this study, despite thedoses and the interval between treatment cycles were same in both arms, the dosedense sequential arm was associated with significantly improved DFS and OS compared to alternating regimen. In addition to NCI Milan Study, the efficacy of dosedense treatment demonstrated significant DFS and OS improvement compared to standard regimens in CALGB 9741 trial whereasno significant DFS and OS difference was observed with dose dense FEC with filgrastim support in GONO-MIG trial (Citron et al., 2003; Venturini et al., 2005).

In a randomized phase II study of AC or epirubicin and cyclophosphamide (EC) given 2 weekly with pegfilgrastim (accelerated) or 3 weekly regimen demonstrated that dosedense regimens were safe with less neutropenia compared to standard every three weeks regimen for patients with early breast cancer (Jones et al., 2009). A grade 3 or 4 neutropenia was not reported in accelerated arm whereas it was reported in $10 \%$ of the patients in standard every three weeks arm. In another phase II study, Ellis and colleagues demonstrated that grade 3 and 4 neutropenia was developed in $26.5 \%$ and $10 \%$ with dose-dense regimen of the patients treated in node-positive breast cancer (Ellis et al., 2002). In contrary to this trials, in our study grade 3 or 4 neutropenia was reported in $21.7 \%$ of the patients treated with dose-dense AC arm.

Our study includes some limitations due to retrospective design and indirect comparison. In our trial, median PFS and OS was similar between treatment arms after multivariate analyses performed for unequal distributions. In our study all the patients who can be treated with chemotherapy were included to study. Another critique limitation of our study that we only had the adverse events data about the hematological and laboratory results only in dose-dense group. Thus we could not compare the adverse events of non-hematological toxicity and hematological toxicities between treatment arms. HER-2 overexpression is believed to be associated with tumor invasion, high grade histology, and poor prognosis (Slamon et al., 1987). Due to the retrospective design, HER-2 distribution between the treatment groups were not similar. Approximately all the patients were treated with adjuvant trastuzumab and multivariate analyses of our study showed no effect of unequal distribution of HER2 positivity on DFS and OS between treatment arms. Despite in randomized trials, no short term cardiotoxicity effect of dose-dense chemotherapy was reported, in our study we have no data about the effect of dose-dense chemotherapy in left ventricular ejection fraction change during chemotherapy (Morris et al., 2009).

Despite dose-dense chemotherapy is recommended in the adjuvant treatment of node-positive breast cancer according to the current breast cancer guidelines, there is still no consensus of the optimal regimen and duration of dose-dense therapy (Senkus et al., 2013; Theriault et al., 2013). In conclusion, in our study the efficacy of dose- 
dense strategies and conventional taxane regimens were similar. Several trials demonstrated the efficacy dosedense taxanes with G-CSF support are safe and feasible and significant effect on DFS and OS in patients with node-positive breast cancer whereas some studies did not show superiority of dose-dense strategies. But the question of the efficacy of dose dense strategies will only be answered in large randomized prospective clinical trials, thus the results of ongoing trials are intriguing. Future studies are needed to define the optimal patients who will receive the greatest benefit from dose-dense therapy.

\section{References}

Bang SM,Heo DS,Lee KH, et al (2000). Adjuvant doxorubicin and cyclophosphamide versus cyclophosphamide, methotrexate, and 5-fluorouracil chemotherapy in premenopausal women with axillary lymph node positive breast carcinoma. Cancer, 89, 2521-6.

Bonadonna G, Valagussa P, Moliterni A, et al (1995). Adjuvant cyclophosphamide, methotrexate, and fluorouracil in nodepositive breast cancer: the results of 20 years of follow-up. N Engl J Med, 332, 901-6.

Bonadonna G, Zambetti M, Moliterni A, et al (2004). Clinical relevance of different sequencing of doxorubicin and cyclophosphamide, methotrexate, and Fluorouracil in operable breast cancer. J Clin Oncol, 22, 1614-20.

Bontenbal M, Creemers GJ, Braun HJ, et al (2005). Phase II to III study comparing doxorubicin and docetaxel with fluorouracil, doxorubicin, and cyclophosphamide as firstline chemotherapy in patients with metastatic breast cancer: results of a dutch community setting trial for the clinical trial group of the comprehensive cancer centre. J Clin Oncol, 23, 7081-8.

Citron ML, Berry DA, Cirrincione C, et al (2003). Randomized trial of dose-dense versus conventionally scheduled and sequential versus concurrent combination chemotherapy as postoperative adjuvant treatment of node-positive primary breast cancer: first report of Intergroup Trial C9741/Cancer and Leukemia Group B Trial 9741. J Clin Oncol, 21, 1431-9.

Early Breast Cancer Trialists' Collaborative Group (1998). Polychemotherapy for early breast cancer: an overview of the randomised trials. Lancet, 352, 930-42.

Early Breast Cancer Trialists' Collaborative Group (2005). Effects of chemotherapy and hormonal therapy for early breast cancer on recurrence and 15-year survival: an overview of the randomised trials. Lancet, 365, 1687-717.

Early Breast Cancer Trialists' Collaborative G, Peto R, Davies C, et al (2012). Comparisons between different polychemotherapy regimens for early breast cancer: metaanalyses of long-term outcome among 100,000 women in 123 randomised trials. Lancet, 379, 432-44.

Eiermann W, Pienkowski T, Crown J, et al (2011). Phase III study of doxorubicin/cyclophosphamide with concomitant versus sequential docetaxel as adjuvant treatment in patients with human epidermal growth factor receptor 2-normal, node-positive breast cancer: BCIRG-005 trial.J Clin Oncol, 29, 3877-84.

Ellis GK, Livingston RB, Gralow JR, et al (2002). Dose-dense anthracycline-based chemotherapy for node-positive breast cancer. J Clin Oncol, 20, 3637-43.

Gogas H, Dafni U, Karina M, et al (2012). Postoperative dose-dense sequential versus concomitant administration of epirubicin and paclitaxel in patients with node-positive breast cancer: 5-year results of the Hellenic Cooperative Oncology Group HE 10/00 phase III Trial. Breast Cancer
Res Treat, 132, 609-19.

Gogia A, Raina V, Deo SV, et al (2014). Taxane and anthracycline based neoadjuvant chemotherapy for locally advanced breast cancer: institutional experience. Asian Pac J Cancer Prev, 15, 1989-92.

Henderson IC, Berry DA, Demetri GD, et al (2003). Improved outcomes from adding sequential Paclitaxel but not from escalating Doxorubicin dose in an adjuvant chemotherapy regimen for patients with node-positive primary breast cancer. J Clin Oncol, 21, 976-83.

Jones RL, Walsh G, Ashley S, et al (2009). A randomised pilot Phase II study of doxorubicin and cyclophosphamide (AC) or epirubicin and cyclophosphamide (EC) given 2 weekly with pegfilgrastim (accelerated) vs 3 weekly (standard) for women with early breast cancer. Br J Cancer, 100, 305-10.

Kimura M, Tominaga T, Takatsuka Y, et al (2010). Randomized trial of cyclophosphamide, epirubicin, and fluorouracil chemotherapy compared with cyclophosphamide, methotrexate, and fluorouracil with node-positive breast cancer in Japan. Breast Cancer, 17, 190-8.

Levine MN, Bramwell VH, Pritchard KI, et al (1998). Randomized trial of intensive cyclophosphamide, epirubicin, and fluorouracil chemotherapy compared with cyclophosphamide, methotrexate, and fluorouracil in premenopausal women with node-positive breast cancer. National Cancer Institute of Canada Clinical Trials Group. J Clin Oncol, 16, 2651-8.

Mackey JR, Martin M, Pienkowski T, et al (2013). Adjuvant docetaxel, doxorubicin, and cyclophosphamide in nodepositive breast cancer: 10-year follow-up of the phase 3 randomised BCIRG 001 trial. Lancet Oncol, 14, 72-80.

Martin M, Segui MA, Anton A, et al (2010). Adjuvant docetaxel for high-risk, node-negative breast cancer. $N$ Engl J Med, 363, 2200-10.

Martin M, Villar A, Sole-Calvo A, et al (2003). Doxorubicin in combination with fluorouracil and cyclophosphamide (i.v. FAC regimen, day 1,21 ) versus methotrexate in combination with fluorouracil and cyclophosphamide (i.v. CMF regimen, day 1,21$)$ as adjuvant chemotherapy for operable breast cancer: a study by the GEICAM group. Ann Oncol, 14, 833-42.

Morris PG, Dickler M, McArthur HL, et al (2009). Dosedense adjuvant Doxorubicin and cyclophosphamide is not associated with frequent short-term changes in left ventricular ejection fraction. J Clin Oncol, 27, 6117-23.

Nabholtz JM, Falkson C, Campos D, et al (2003). Docetaxel and doxorubicin compared with doxorubicin and cyclophosphamide as first-line chemotherapy for metastatic breast cancer: results of a randomized, multicenter, phase III trial. J Clin Oncol, 21, 968-75.

Norton L, Simon R (1986). The Norton-Simon hypothesis revisited. Cancer Treat Rep, 70, 163-9.

Ozdemir N, Aksoy S, Zengin N, et al (2012). Taxanes in the adjuvant treatment of node-negative breast cancer patients. J BUON, 17, 27-32.

Sakr H, Hamed RH, Anter AH, et al (2013). Sequential docetaxel as adjuvant chemotherapy for node-positive or/and T3 or T4 breast cancer: clinical outcome (Mansoura University). Med Oncol, 30, 457.

Senkus E, Kyriakides S, Penault-Llorca F, et al (2013). Primary breast cancer: ESMO Clinical Practice Guidelines for diagnosis, treatment and follow-up. Ann Oncol, 24, 7-23.

Siegel R, Ma J, Zou Z, et al (2014). Cancer statistics, 2014. CA Cancer J Clin, 64, 9-29.

Slamon DJ, Clark GM, Wong SG, et al (1987). Human breast cancer: correlation of relapse and survival with amplification of the HER-2/neu oncogene. Science, 235, 177-82. 
Sparano JA, Wang M, Martino S, et al (2005). Phase III study of doxorubicin cyclophosphamide followed by paclitaxel or docetaxel given every 3 weeks or weekly in patients with axillary node-positive or high-risk node-negative breast cancer: results of North American Breast Cancer Intergroup Trial E1199. Breast Cancer Res Treat, 94, 516.

Sparano JA, Wang M, Martino S, et al (2008). Weekly paclitaxel in the adjuvant treatment of breast cancer. $N$ Engl J Med, 358, $1663-71$.

Swain SM, Tang G, Geyer CE, et al (2013). Definitive results of a phase III adjuvant trial comparing three chemotherapy regimens in women with operable, node-positive breast cancer: the NSABP B-38 trial. J Clin Oncol, 31, 3197-204.

Theriault RL, Carlson RW, Allred C, et al (2013). Breast cancer, version 3.2013: featured updates to the NCCN guidelines. $J$ Natl Compr Canc Netw, 11, 753-60.

Venturini M, Del Mastro L, Aitini E, et al (2005). Dose-dense adjuvant chemotherapy in early breast cancer patients: results from a randomized trial. J Natl Cancer Inst, 97, 1724-33. 